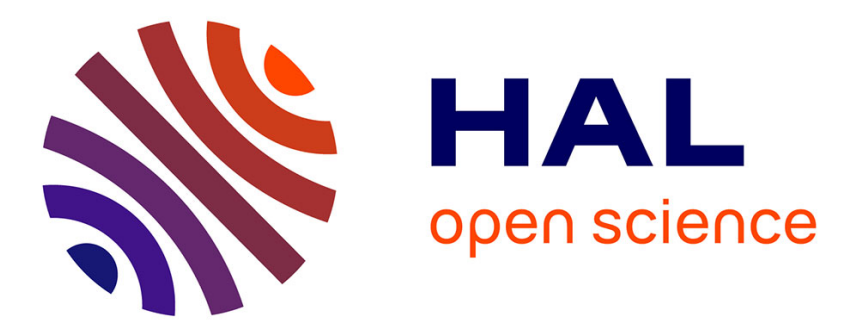

\title{
Field Emission from As-Grown and Ion-Beam-Sharpened Diamond Particles Deposited on Silicon Tips
}

\author{
A. Stepanova, V. Zhirnov, L. Bormatova, E. Givargizov, E. Mashkova, V. Y. \\ Molchanov
}

\section{> To cite this version:}

A. Stepanova, V. Zhirnov, L. Bormatova, E. Givargizov, E. Mashkova, et al.. Field Emission from AsGrown and Ion-Beam-Sharpened Diamond Particles Deposited on Silicon Tips. Journal de Physique IV Proceedings, 1996, 06 (C5), pp.C5-103-C5-106. 10.1051/jp4:1996516 . jpa-00254395

\section{HAL Id: jpa-00254395 https://hal.science/jpa-00254395}

Submitted on 1 Jan 1996

HAL is a multi-disciplinary open access archive for the deposit and dissemination of scientific research documents, whether they are published or not. The documents may come from teaching and research institutions in France or abroad, or from public or private research centers.
L'archive ouverte pluridisciplinaire HAL, est destinée au dépôt et à la diffusion de documents scientifiques de niveau recherche, publiés ou non, émanant des établissements d'enseignement et de recherche français ou étrangers, des laboratoires publics ou privés. 


\title{
Field Emission from As-Grown and Ion-Beam-Sharpened Diamond Particles Deposited on Silicon Tips
}

\author{
A.N. Stepanova, V.V. Zhirnov, L.V. Bormatova, E.I. Givargizov, E.S. Mashkova* \\ and V.A. Molchanov* \\ Institute of Crystallography, Russian Academy of Sciences, Moscow 117334, Russia \\ * Institute of Nuclear Physics, Moscow State University, Moscow 119899, Russia
}

\begin{abstract}
Ion-beam bombardment/milling was used for sharpening of diamond particles deposited on ends of silicon tips. Radii curvature of diamond coating down to about $20 \mathrm{~nm}$ have been formed in such a way. Field emission experiments with sharpened diamond coated emitters have shown that the ion beam treatment effects a considerable shift of current-voltage characteristics of in the lower voltage region.
\end{abstract}

\section{INTRODUCTION}

The discovery of possibility to realize the negative electron affinity (NEA) for the (111) - face of diamond [1] stimulated strongly research in field emission of diamond and diamond-like materials [2-4]. The obtaining of relatively large field-emission currents from tipped diamond surfaces in comparison with flat ones [5] was interpreted as a sequence of the NEA phenomenon, although a mechanism of such an emission remains unclear.

From practical point of view, the use of the tip emitters prepared from single-crystalline diamond [5] seems to be unrealistic due to extremely high cost of the material. Another approach to solving of the problem based on using of diamond particles or films deposited onto high-aspect-ratio silicon tips has been proposed [6]. In the approach, hot-filament CVD process is preferable for the deposition of diamond, because such a process enables to prepare high-quality (poly-crystalline) material $[7,8]$ with reproducible electrophysical properties. However, radii of curvature of the diamond coated emitters are too large for obtaining of sufficient currents at moderate electric fields. emitters.

In this paper, a process of ion milling is used in order to prepare sharp, reproducible diamond

\section{EXPERIMENTAL}

The diamond-coated silicon-tip emitters were prepared according to the procedures described in papers [7,9]. The emitters were formed on the butt-ends of [111]-oriented silicon rods and, then, all of them, except one, were removed so that characteristics of single emitters could be measured.

Then, the samples were treated by beams of single-charged argon ions at energies $30 \mathrm{keV}$, ion currents 0.2 to $0.3 \mathrm{~mA} / \mathrm{cm}^{2}$, and fluences $2-5 \cdot 10^{18}$ ion $/ \mathrm{cm}^{2}$. The ions were directed along axes of the emitters. The procedure was performed at $60^{\circ} \mathrm{C}$. In more detail, the sharpening procedure was described in papers $[10,11]$.

After the sharpening, some samples were annealed in atomic and/or molecular hydrogen at 600 $700^{\circ} \mathrm{C}$ during time periods 15 to $30 \mathrm{~min}$.

Field-emission characteristics of the samples before and after the treatments were taken according to the technique described in [12]. Both I-V and FN characteristics were plotted. 


\section{RESULTS AND DISCUSSIONS}

\subsection{Ion-milling}

The ion beam had a gaussian density distribution. In the center of the beam where ion densities were maximal, at sufficiently-large ion fluences diamond coating was sometimes etched off completely so that silicon tip itself became exposed, while at a periphery of the beam a partial diamond sharpening occurred. Practically, with our post-mounted tips, ion fluences were chosen so that to reach an optimal sharpening and avoid the exposure of silicon.

An example of the ultrasharp diamond tip prepared by the technique is given in Fig. 1.

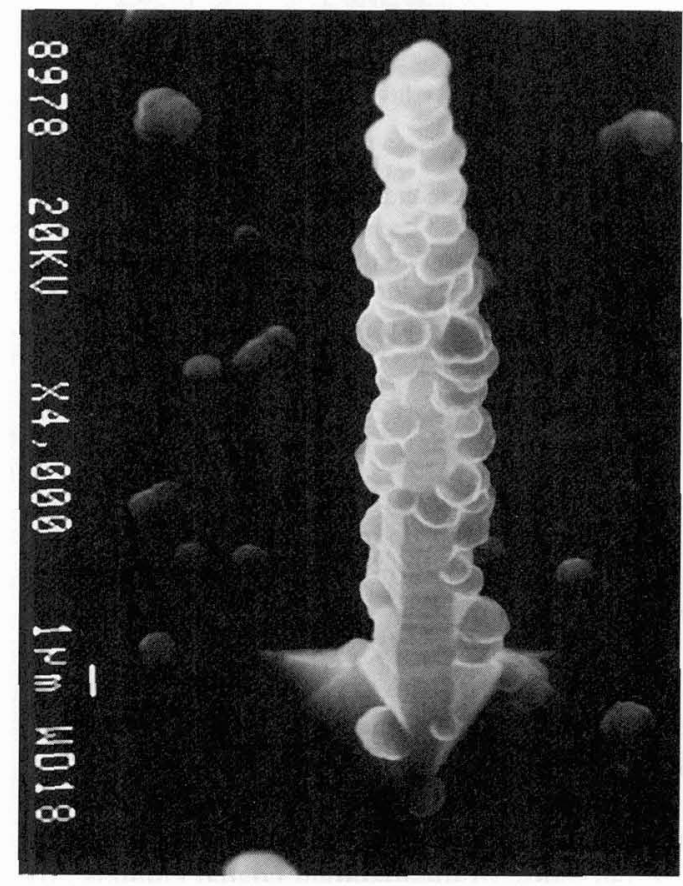

a)

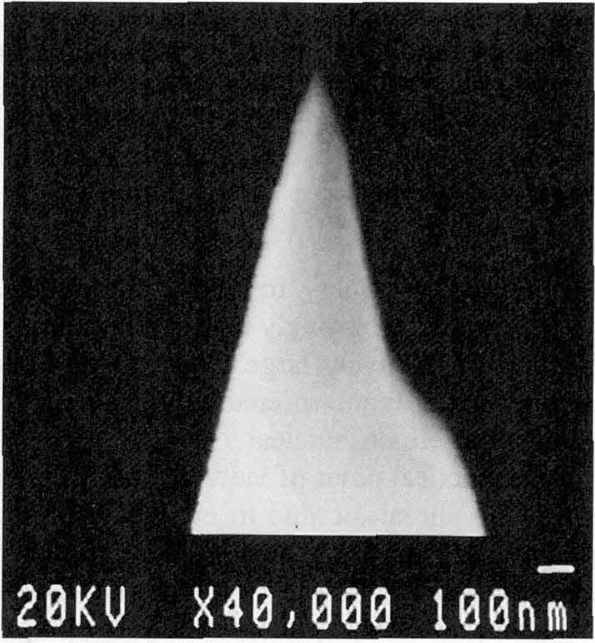

b)

Figure 1: Diamond-coated silicon-tip emitter: a) - as-grown (before sharpening); b) - sharpened one.

\subsection{Field emission from sharpened diamond tips}

In Fig. 2 are shown emission characteristics obtained from the same sample before and after the sharpening. As it is seen, the voltage corresponding to the onset of the emission, at measurable (in our experiments) $10^{-9} \mathrm{~A}$, decreased strongly (from about $1300 \mathrm{~V}$ down to about $150 \mathrm{~V}$ ) when the emitter was sharpened. This decrease we connect with at least two factors:

(a) decrease of the curvature radius of the emitter from about $0.5 \mathrm{~mm}$ to about $20 \mathrm{~nm}$;

(b) tentative formation of defects in the emitter during the ion-beam bombardment with corresponding improvement of the field emission, as it was supposed by $\mathrm{Zhu}$ et al [13].

The latter effect is confirmed by our results with annealings of the emitters. In Fig. 3, the curve 1 corresponds to a sharpened emitter before the heat treatment, while the curve 2 - after its annealing $\left(650^{\circ} \mathrm{C}, 15 \mathrm{~min}\right)$ in atomic hydrogen (the treatment was held inside an equipment for hot-filament CVD 
process, at the temperature of the filament $2000^{\circ} \mathrm{C}$ ). The curve 3 was obtained after an annealing of the same emitter in molecular hydrogen at $650-700^{\circ} \mathrm{C}, 15 \mathrm{~min}$.

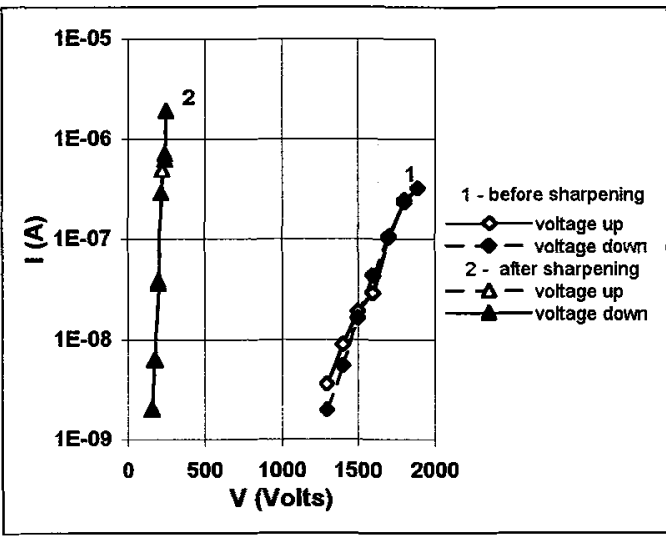

a)

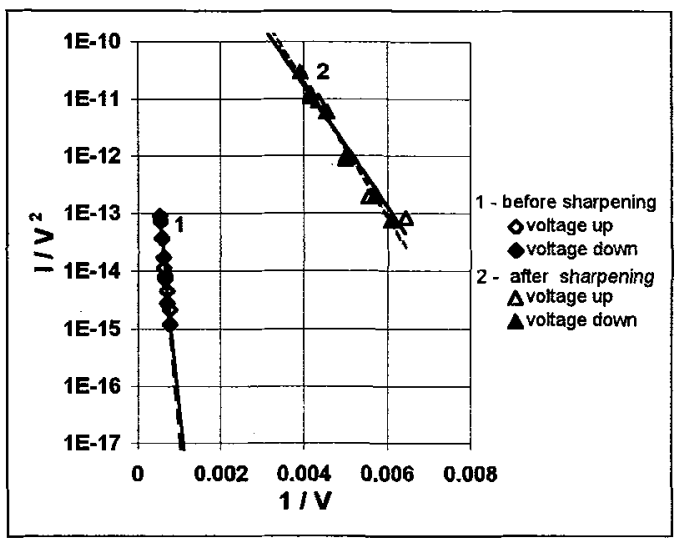

b)

Figure 2: I-V characteristics and FN plots of the same diamond emitter before and after sharpening.

From comparison of the curves it is seen that after the annealings the currents decreased strongly, for several orders of magnitude.

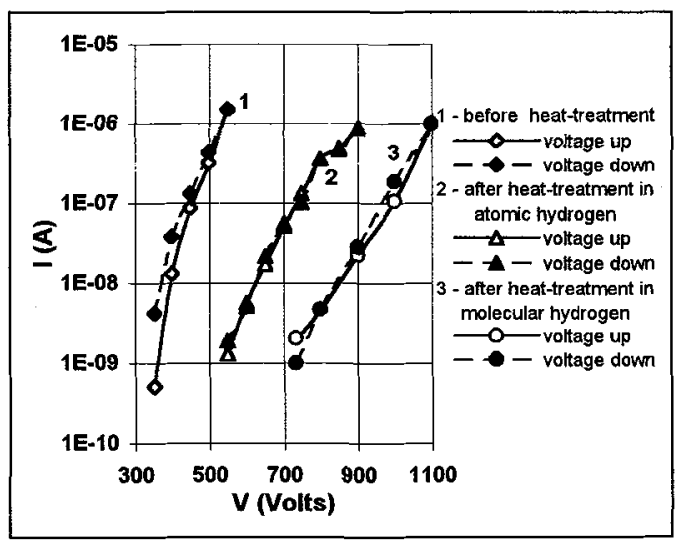

Figure 3: Changes of I-V characteristics of a sharpened diamond emitter as a result of annealing of the emitter in atomic hydrogen and, then, in molecular hydrogen

One of the explanation of the effects is that the annealings remove defects formed at the sharpening and, in such a way, deteriorate emission properties of the diamond. In particular, the action of atomic hydrogen can be more effective because, as is known, it is able to dissolve effectively atomic carbon. Such a carbon can be formed preferentially at the surface. Another possibility is that annealing may change the silicon/diamond interface structure asa well as diamond surface. Additional experiments are needed to investigate the ion milling/annealing effects on crystal structure and surface/interface properties of diamond coating.

The more weak action of molecular hydrogen is shown in Fig. 4. Here, the procedure of annealing in atomic hydrogen was excluded, and the annealing effect was markedly decreased.

In general, the annealing effects need in more detailed (including microstructural) investigations. 


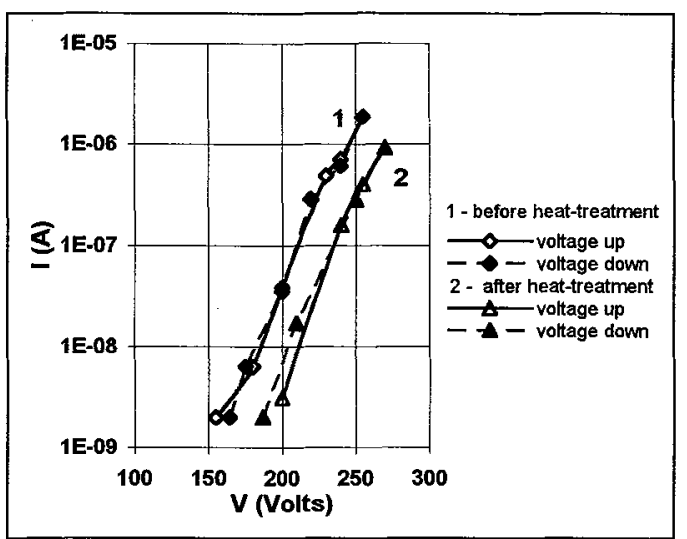

Figure 4: A change of $I-V$ characteristics of a sharpened diamond emitter as a result of annealing in molecular hydrogen

\section{CONCLUSIONS}

1. Ion-beam bombardment/milling was effectively used for ultra-sharpening of diamond particles deposited on ends of silicon tips. Radii curvature down to about $20 \mathrm{~nm}$ can be formed in such a way. 2. Ion beam treatment of diamond coated field emitters effects a considerable shift of current-voltage characteristics of in the lower voltage region.

\section{References}

[1] Himpsel F.J., Knapp I.A., Van Vechten J.A. and Eastman D.E., Phys. Rev. B20 (1979) 624-627.

[2] Wang C., Garcia A., Ingram D.C. and Kordesh M.E., Electr. Lett. 27 (1991) 1459-1462.

[3] Xu N.S., Latham R.V. and Tzeng Y., Electr. Lett. 29 (1993) 1596-1599.

[4] Geis M.W., Twichell J.C., McCaulay J. and Okano K., Appl. Phys. Lett. (1995) 1328-1330.

[5] Geis M.W., Twichell J.C., Bozler C.O., Rathman D.D, Efremov N.N, Krohn K.E., Hollis M.A., Uttaro R. and Lyszczard T.M., "Diamond field-emission cathodes, Tech. Dig. of the 6th Intern. Vac. Microel. Conf. (Newport, RI, USA, July 1993) 160-161 (unpublished).

[6] Givargizov E.I., J. Vac. Sci. Technol. B15 (1995) 414-417.

[7] Stepanova A.N., Aksenova L.L., Kuznetsov A.V., Rakova E.V. and Givargizov E.I., Matter. Lett. 22 (1995) 285-288.

[8] Givargizov E.I., Aksenova L.L., Galstyan V.G., Kiselev A.N., Kuznetsov A.V., Muratova V.I., Rakova E.V. and Stepanova A.N., J. Crystal Growth 162 (1996) 73-78.

[9] Givargizov E.I., J. Vac. Sci. Technol. B11 (1993) 449-453.

[10] Mashkova E.S., Molchanov V.A., Stepanova A.N., Givargizov E.I. and Muratova V.I., Physics, Chemistry, and Mechanics of Surfaces, 11, No. 2 (1995) 5-12.

[11] Mashkova E.S., Molchanov V.A., Stepanova A.N., Muratova V.I., Aksenova L.L. and Givargizov E.I., Physics, Chemistry, and Mechanics of Surfaces (to be published).

[12] Givargizov E.I., Zhirnov V.V., Stepanova A.N., Rakova E.V., Kiselev A.N. and Plekbanov P.S., Appl. Surf. Sci. 87/88 (1995) 24-30.

[13] Zhu W., Kochanski G.P., Jin S., Seibles L., Jacobson D.C. McComack M. and White A.E., Appl. Phys. Lett. 67 (1995) 1157-1159. 